
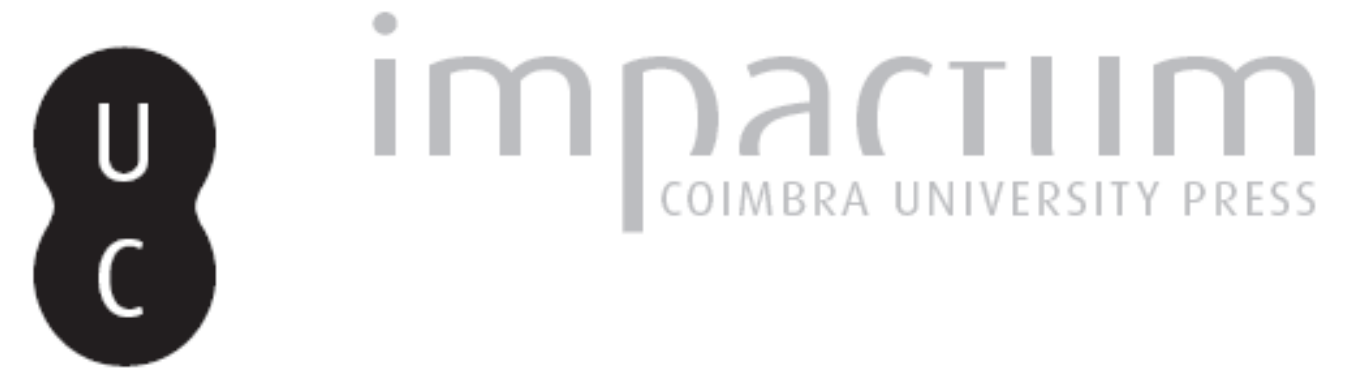

\title{
Crimes públicos e crimes semi-públicos: quando denunciar?
}

Autor(es): $\quad$ Costa, Diogo Pinto da

Publicado por: Imprensa da Universidade de Coimbra

URL persistente:

URI:http://hdl.handle.net/10316.2/33109

DOI:

DOI:http://dx.doi.org/10.14195/1647-8630_18_7

Accessed : $\quad$ 26-Apr-2023 11:37:12

A navegação consulta e descarregamento dos títulos inseridos nas Bibliotecas Digitais UC Digitalis, UC Pombalina e UC Impactum, pressupõem a aceitação plena e sem reservas dos Termos e Condições de Uso destas Bibliotecas Digitais, disponíveis em https://digitalis.uc.pt/pt-pt/termos.

Conforme exposto nos referidos Termos e Condições de Uso, o descarregamento de títulos de acesso restrito requer uma licença válida de autorização devendo o utilizador aceder ao(s) documento(s) a partir de um endereço de IP da instituição detentora da supramencionada licença.

Ao utilizador é apenas permitido o descarregamento para uso pessoal, pelo que o emprego do(s) título(s) descarregado(s) para outro fim, designadamente comercial, carece de autorização do respetivo autor ou editor da obra.

Na medida em que todas as obras da UC Digitalis se encontram protegidas pelo Código do Direito de Autor e Direitos Conexos e demais legislação aplicável, toda a cópia, parcial ou total, deste documento, nos casos em que é legalmente admitida, deverá conter ou fazer-se acompanhar por este aviso.

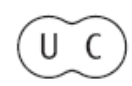




\section{Crimes públicos e crimes semi-públicos. Quando denunciar?"}

Diogo Pinto da Costa²

\section{A investigação criminal (noção)}

A afirmação de determinado facto como crime $^{3}$ implica sempre a averiguação dos pressupostos da punição criminal. Ou seja, para se dizer que se verificou um facto (ou uma conduta) susceptível de constituir crime, para lhe que seja atribuída existência jurídico-penal, o mesmo tem de ser percepcionado e recebido pelo sistema de administração da justiça penal mediante a iniciativa do desencadeamento da investigação da sua prática e, posteriormente, a decisão de o submeter, ou não, a julgamento.

A investigação criminal visa reunir um conjunto de dados e elementos que possam comprovar os factos denunciados ou de que se teve conhecimento, a identificação dos respectivos intervenientes, o grau de responsabilidade na sua prática e o apuramento dos seus efeitos ou resultados em ordem ao correspondente enquadramento na tipologia descrita na lei; visa, no fundo, afirmar a existência ou inexistência dos pressupostos da responsabilidade criminal. Assim, e para além das particularidades concretas de cada crime, há sempre que averiguar e apurar, tanto quanto possível: a hora, dia, mês e ano do facto; o local onde o mesmo ocorreu; o circunstancialismo objectivo e subjectivo que rodeou a sua prática; a identificação da vítima ${ }^{4}$ e do agente do crime; o grau de culpa do agente; as consequências desse mesmo facto, com recurso, se necessário, ao exame pericial (fundamental para atestar não

1 O presente texto corresponde, com actualizações, à Comunicação com o mesmo título apresentada pelo autor no $7^{\circ}$ Congresso Nacional de Medicina Legal (Tomar, 7-8 de Novembro de 2008).

2 Chefe do Gabinete de Assessoria Jurídica do Instituto Nacional de Medicina Legal, I.P.; Assistente da Faculdade de Medicina do Porto.

3 Crime é todo o facto humano voluntário descrito na lei, ao qual corresponde a aplicação de uma pena.

4 Tratando-se, obviamente, de crimes com vítimas. 
só as causas e as consequências do facto mas, mesmo, em certos casos, a sua prática); os restantes elementos de prova disponíveis.

A investigação criminal é feita na fase de inquérito, o qual (com excepção óbvia dos processos especiais ${ }^{5}$ ) constitui o expediente único e preparatório da decisão final a tomar pelo Ministério Público face à situação jurídico-criminal configurada (acusar ou não acusar). O inquérito compreende o conjunto das diligências que visam investigar a existência do crime, determinar o(s) seu(s) agente(s) e apurar a sua responsabilidade, descobrindo e recolhendo provas que permitam, a final, decidir pela acusação ou pelo arquivamento do processo $^{6}$. Essas diligências realizam-se sempre de acordo com as formalidades e regras ${ }^{7}$ previstas no Código de Processo Penal (CPP).

\section{A intervenção pericial dos serviços médico-legais (fundamento legal)}

A direcção do inquérito cabe exclusivamente ao Ministério Público, assistido pelos órgãos de polícia criminal, que assim ficam na sua dependência funcional. Sendo o Ministério Público o responsável máximo pela investigação criminal, há que cumprir em relação a ele a regra da transmissão de qualquer denúncia que tenha sido feita, cabendo-lhe ainda, caso a caso, decidir pela delegação da investigação nos órgãos de polícia criminal ou pela realização por eles de uma ou mais diligências. Enquanto titular do inquérito, compete ao Ministério Público dispor materialmente da investigação, com o auxílio dos referidos órgãos de polícia criminal, que dele estão dependentes funcionalmente, sem que essa dependência funcional ponha em causa a autonomia organizativa, administrativa, técnica e disciplinar das polícias que prestam essa coadjuvação.

«O conceito de direcção do inquérito conferida ao Ministério Público pelos art. ${ }^{\circ}$ s $53^{\circ}$ e $263^{\circ}$ do CPP não exige a direcção real e efectiva, contentando-se com uma direcção funcional da mesma» (Acórdão da Relação de Lisboa, de 4 de Maio de 1990; CJ XV, tomo 3, 158).

As diligências de prova são em regra reduzidas a auto, sendo-o obrigatoriamente a denúncia quando oral, bem como os actos praticados pelo Juiz de Instrução Criminal ou por ele autorizados, e as declarações para memória futura. Em regra, o Ministério Público pode conferir aos órgãos de polícia

5 São processos especiais o processo sumário, o abreviado e o sumaríssimo - art.s $381^{\circ}$ a $398^{\circ}$ do CPP.

6 Nos termos dos artigos $276 .^{\circ}$, n. $^{\circ} 1,277 .^{\circ}$, e $283 .^{\circ}$ do Código de Processo Penal (actualmente em vigor a versão introduzida pela Lei n. ${ }^{\circ} 48 / 2007$, de 29 de Agosto (15. a alteração ao Código de Processo Penal, aprovado pelo Decreto -Lei n. ${ }^{\circ}$ 78/87, de 17 de Fevereiro).

7 Na terminologia anglo-saxónica: no respeito pelo due process of law. 
criminal o encargo de proceder a quaisquer diligências de investigação relativas ao inquérito, dado que nos termos da lei processual penal compete a esses órgãos policiais coadjuvar as autoridades judiciárias com vista à realização das finalidades do processo.

Sempre que no âmbito do inquérito surja a necessidade de apreciar determinado facto no âmbito do esclarecimento de uma questão jurídica, e tal envolva especiais conhecimentos de natureza médica ou biológica, há lugar à perícia médico-legal, obrigatória nos termos do art. $151^{\circ}$ do CPP (Acórdão do Supremo Tribunal de Justiça, de 9-5-1990).

A realização de perícias médico-legais em sede penal encontra-se cometida aos serviços médico-legais nos termos da legislação processual penal (cf. o art. ${ }^{\circ} 159 .^{\circ}$ do CPP) e da lei que regulamenta a realização das perícias médicolegais e forenses (Lei n. ${ }^{\circ}$ 45/2004, de 19 de Agosto).

Os serviços médico-legais são, pois, (os) serviços de apoio técnico pericial médico-legal aos tribunais e ao Ministério Público na administração da justiça, encontrando-se organizados no âmbito do Instituto Nacional de Medicina Legal, I.P. (INML, I.P.) ${ }^{8}$. Em sede de realização dos exames e perícias que nessa qualidade lhe são solicitadas, os serviços médico-legais (os serviços técnicos das delegações e os gabinetes médico-legais do INML, I.P.) intervêm:

a) mediante despacho da autoridade judiciária competente, nos termos da lei de processo (cf. o art. $3^{\circ}$, n. ${ }^{\circ} 1$, da Lei n. ${ }^{\circ} 45 / 2004$, de 19 de Agosto) ${ }^{9}$;

b) mediante solicitação dos órgãos de polícia criminal, na prossecução das suas atribuições legais e nos termos de competências próprias ou delegadas pela autoridade judiciária competente (cf. art. $2^{\circ}$ da Lei de Investigação Criminal - Lei n. ${ }^{\circ}$ 49/2008, de 27 de Agosto, e Circular da PGR n. ${ }^{\circ}$ 6/ 2002, de 08-3), excepto a perícia que envolva a realização de autópsia médico-legal, bem como a prestação de esclarecimentos e realização de nova perícia nos termos do art. $158^{\circ}$ do CPP (art. $270^{\circ}$, n. ${ }^{\circ} 2$, do CPP);

c) no âmbito do art. $4^{\circ}$ da Lei n. ${ }^{\circ}$ 45/2004, de 19 de Agosto (recebimento de denúncias de crimes), podendo a solicitação da realização do exame médico-legal ser feita pela própria vítima (ou por outra pessoa que denuncie o crime), pelo serviço de saúde que preste assistência à vítima,

8 Ao INML, I.P., cabe, no exercício das suas atribuições periciais forenses, cooperar com os tribunais e demais serviços e entidades que intervêm no sistema de administração da justiça, realizando os exames e as perícias de medicina legal e forenses que lhe forem solicitados, nos termos da lei, bem como prestar-lhes apoio técnico e laboratorial especializado, no âmbito das suas atribuições - cf. o art. $3^{\circ}$, n. $^{\circ} 2$, b) da lei orgânica do INML, I.P. (Decreto-lei n. ${ }^{\circ}$ 131/2007, de 27 de Abril).

9 No âmbito penal, em clara e expressa consonância, aliás, com o disposto no n. ${ }^{\circ} 1$ do art. $159^{\circ}$ do CPP. 
ou por entidade com competência legal de intervenção para protecção dos interesses da vítima ${ }^{10}$;

d) a solicitação da entidade policial, em sede de exame do local (de ocorrência de óbito), nos termos da alínea c do n. ${ }^{\circ} 1$ do art. $16^{\circ}$ da Lei n. ${ }^{\circ}$ 45/2004, de 19 de Agosto;

e) nos termos do disposto no n. ${ }^{\circ} 13$ do art. $16^{\circ}$ da Lei n. ${ }^{\circ}$ 45/2004, de 19 de Agosto, para realização de exame do hábito externo de cadáver na situações em que se revele necessário auxiliar o Ministério Público na decisão quanto à realização (ou à dispensa) da autópsia.

\section{0 impulso processual: crimes de natureza pública e crimes de natureza semi-pública ${ }^{11}$}

Em regra, e fala-se a este propósito do princípio da oficialidade, «a iniciativa e o impulso processuais da investigação prévia e da submissão a

10 A intervenção dos serviços médico-legais pode ocorrer mediante a solicitação das Comissões de Protecção de Crianças e Jovens (CPCJ), no âmbito das suas competências de protecção das crianças e jovens em risco, previstas no Decreto-Lei n. ${ }^{\circ}$ 147/99, de 1 de Setembro, devendo, porém, ter-se em atenção o seguinte:

a) Nos termos do art. $18^{\circ}$, n. $^{\circ} 2$, b), do Decreto-Lei n. ${ }^{\circ}$ 147/99, de 1 de Setembro, compete às CPCJ promover acções e colaborar com as entidades competentes tendo em vista a detecção dos factos e situações que, na área da sua competência territorial, afectem os direitos e interesses da criança e do jovem, ponham em perigo a sua segurança, saúde, formação ou educação ou se mostrem desfavoráveis ao seu desenvolvimento e inserção social;

b) Ora, no exercício de tal competência, tem cabimento a solicitação da realização de exames médico-legais a crianças ou jovens em situação de perigo [que na maioria dos casos serão menores, podendo embora ser maiores entre os 18 e os 21 anos - cf. a definição de criança e de jovem constante do n. ${ }^{\circ} 5^{\circ}$, a) do Decreto-Lei n. ${ }^{\circ}$ 147/99, de 1 de Setembro];

c) Porém, estes exames visam permitir fazer um diagnóstico da situação em que o menor se encontra, para efeito de tomada de decisão sobre a adopção de medidas de protecção, e não para efeito de investigação de ilícitos criminais; ou seja, os exames que as CPCJ podem requerer ao INML, I.P., não constituem exames periciais para acautelar a investigação de um crime;

d) Exames com tal fim são os requeridos nos termos do art. 3. . da Lei 45/2004, de 19 de Agosto;

e) Consequentemente, nos casos em que se indiciem crimes públicos, os relatórios de exames ou perícias requeridos pelas CPCJ devem ser remetidos ao Ministério Público, na sua versão original (acompanhando eventual denúncia nos termos do art. $242^{\circ}$ do CPP), podendo o INML, I.P., remeter cópia daqueles exames ou perícias às CPCJ.

f) A intervenção dos serviços médico-legais em matéria de promoção e protecção (de crianças e jovens em risco), pode também ter lugar a solicitação do Juiz em sede de processo de promoção e protecção, caso em que não se exige do INML, I.P., qualquer comunicação (ou eventual denúncia) para além da entrega do relatório pericial ao competente juiz do tribunal de família e menores.

11 As designações pelas quais se distinguem os crimes tendo em conta os respectivos requisitos para instauração do processo penal são doutrinárias, não constando da lei substantiva ou processual penal; por simplificação terminológica utilizam-se as expressões "crimes públicos "e "crimes semi-públicos". 
julgamento das infracções criminais competem oficiosamente às entidades públicas a quem a lei confere o encargo daquela investigação e aos tribunais criminais» (Simas Santos e Leal-Henriques, 2003, p. 329) ${ }^{12}$.

Este princípio sofre limitações, dado existirem, ao lado de crimes em que o procedimento criminal é desencadeado oficiosamente pelo Ministério Público, que exerce a acção penal com plena autonomia - os chamados crimes públicos ${ }^{13}$-, crimes relativamente aos quais, atenta a sua natureza, se exige diferentes requisitos para a respectiva promoção processual:

- crimes cujo procedimento criminal depende de apresentação de queixa por parte do ofendido ${ }^{14}$, ou de terceiros que para tal tenham também legitimidade ${ }^{15}$ - art. $49^{\circ}$ do CPP - assim se conferindo legitimidade ao Ministério Público para exercer a acção penal - os crimes semi-públicos ${ }^{16}$; - crimes em que a legitimidade do Ministério Público para exercer a acção penal necessita de ser integrada não só com uma queixa, mas também com uma acusação particular - os crimes particulares. ${ }^{17}$

Em suma, de acordo com a fonte do impulso para instauração de procedimento criminal, podem os crimes ser classificados como crimes públicos, semi-públicos, e particulares.

O procedimento criminal tem como fase primeira o inquérito. Este inicia-se com a aquisição da "notícia do crime», ${ }^{18}$ através da denúncia (da mera denúncia, nos crimes públicos), da queixa (crimes semi-públicos), ou da queixa e constituição de assistente (crimes particulares).

A denúncia consiste numa comunicação, que pode ser verbal (reduzindose então a escrito com elaboração do respectivo Auto) ou escrita, através

12 Simas Santos, M. e Leal-Henriques, M. (2003): Noções Elementares de Direito Penal. Lisboa: Rei dos Livros.

13 Os crimes dizem-se de natureza pública quando basta a notícia do crime para que o Ministério Público exerça a acção penal, independentemente de qualquer manifestação de vontade por parte do ofendido (art. ${ }^{\circ} 48^{\circ}$ do Código de Processo Penal).

14 Ofendido é o titular do interesse que a lei especialmente quis proteger com a incriminação - art. $^{\circ} 68 .^{\circ}$, n. $^{\circ} 1$, a).

15 As pessoas referidas nas alíneas b) a e) do n. ${ }^{\circ} 1$ do art. ${ }^{\circ} 68 .^{\circ}$ do $\mathrm{CPP}$, nas quais se incluem os representantes legais dos incapazes, designadamente dos menores de 16 anos.

16 Nestes casos, o Ministério Público pode, mesmo assim, dar início ao procedimento criminal nas situações previstas no n. ${ }^{\circ} 5$ do art. $^{\circ} 113$. $^{\circ}$ do Código Penal.

17 Nos crimes particulares, é necessário que o ofendido se constitua assistente (para o que deve pagar respectiva taxa de constituição de assistente, ou - o que será difícil para a grande maioria dos cidadãos - conseguir isenção mediante requerimento de apoio judiciário na Segurança Social) e deduza acusação particular - art. $^{\circ} 50 .^{\circ}$ do CPP.

18 Existe processo de inquérito a partir do momento em que determinado expediente (auto de notícia ou denúncia) é registado e autuado como inquérito pelo Ministério Público (art. $262^{\circ}$ do CPP). 
da qual é levada ao conhecimento do Ministério Público a suspeita de que foi cometido um crime. Se o crime em questão não exige para a respectiva promoção processual a queixa ou a acusação particular, a denúncia é, pois, obrigatória (ainda que os agentes do crime não sejam conhecidos) para as entidades policiais e para os funcionários, na acepção do art. $386 .^{\circ}$ do Código Penal (CP), quanto a crimes públicos de que tomarem conhecimento no exercício das suas funções e por causa delas (art..$^{\circ} 242^{\circ}$ do CPP).

$\mathrm{O}$ art. ${ }^{\circ} 386 .^{\circ}$, n. ${ }^{\circ} 1$, do $\mathrm{CP}$ dá-nos o conceito de funcionário que aqui se aplica:

$$
\text { «Art. } 386^{\circ}
$$

Conceito de funcionário

1 - Para efeito da lei penal a expressão funcionário abrange:

a) O funcionário civil;

b) $O$ agente administrativo; $e$

c) Quem mesmo provisória ou temporariamente, mediante remuneração ou a título gratuito, voluntária ou obrigatoriamente, tiver sido chamado a desempenhar ou a participar no desempenho de uma actividade compreendida na função pública administrativa ou jurisdicional, ou, nas mesmas circunstâncias, desempenhar funções em organismos de utilidade pública ou nelas participar.

(...)»

A denúncia pode ser feita por qualquer pessoa, sem prejuízo da existência de denúncia obrigatória para certas entidades e categorias de pessoas (nos termos do art. $386^{\circ}$ do $\mathrm{CP}$ ).

Por seu turno, a queixa consiste em dar-se conhecimento ao Ministério Público (ou à autoridade judiciária ou de polícia que o transmitirá àquele) do facto para que seja promovido o respectivo processo, sendo um acto pessoal que deve ser praticado pelo «titular dos interesses que a lei quis especialmente proteger com a incriminação» (art. 113 ${ }^{\circ}, \mathrm{n}^{\circ} 1$, do $\mathrm{CP}$ ) ou, no caso deste ser incapaz, por uma das pessoas elencadas no $\mathrm{n}^{\circ} 3$ do art. $113^{\circ}$ do $\mathrm{CP}$, agindo em representação daquele (representante legal, cônjuge não separado judicialmente de pessoas e bens, descendentes e na falta deles, aos ascendentes, irmãos e seus descendentes).

Têm legitimidade para exercer o direito de queixa de que são titulares os indivíduos de idade superior a dezasseis anos que não apresentem incapacidades de exercício impeditivas da apresentação da queixa (v. g. anomalia psíquica que comprometa a percepção do significado e alcance da queixa).

$\mathrm{O}$ exercício do direito de queixa encontra-se regulado no art. $113^{\circ}$ do $\mathrm{CP}$, nos seguintes termos: 
a) Se o ofendido for menor de 16 anos ou não possuir discernimento para entender o alcance e o significado do exercício do direito de queixa, este pertence ao representante legal e, na sua falta, às pessoas e pela ordem a seguir indicadas (salvo se alguma dessas pessoas houver comparticipado no crime):

a) Ao cônjuge sobrevivo não separado judicialmente de pessoas e bens, aos descendentes e aos adoptados e aos ascendentes e aos adoptantes;

b) Aos irmãos e seus descendentes e à pessoa que com o ofendido vivesse em condições análogas às dos cônjuges.

São "representantes legais" em sentido próprio ou estrito, para efeito do exercício do direito de queixa em processo penal:

a) relativamente a menores de 16 anos:

- os pais do menor ou o progenitor que exerça o poder paternal ${ }^{19}$ (na falta de decisão judicial que atribua o exercício do poder paternal apenas a um dos progenitores, o poder paternal é exercido em conjunto);

- o tutor, nomeado pelos pais ou pelo tribunal;

b) relativamente aos indivíduos maiores de 16 anos que não possuem discernimento para entender o alcance e o significado do exercício do direito de queixa:

- Os pais do menor, ou o progenitor que exerça o poder paternal (de menor entre os 16 e os 18 anos);

- o tutor, nomeado pelos pais ou pelo tribunal (quando a vítima é maior de 18 anos).

Quando o procedimento criminal depender de queixa, o Ministério Público pode dar início ao procedimento no prazo de seis meses a contar da data em que tiver tido conhecimento do facto e dos seus autores, sempre que o interesse do ofendido o aconselhar e:

a) Este for menor ou não possuir discernimento para entender o alcance e o significado do exercício do direito de queixa; ou

b) $\mathrm{O}$ direito de queixa não puder ser exercido porque a sua titularidade caberia apenas ao agente do crime (n. 5 do art. $113^{\circ}$ do $\mathrm{CP}$ ).

A queixa concretiza-se mediante «requerimento, feito segundo a forma e no prazo prescritos, através do qual o titular do respectivo direito, em regra o ofendido, exprime a sua vontade de que se verifique procedimento penal por um crime cometido contra ele ou contra pessoa com ele relacionada»

19 A lei civil transformou o "poder paternal» em «responsabilidades parentais»: Lei n. ${ }^{\circ}$ 61/2008, de 31de Outubro (altera o regime jurídico do divórcio). 
(Figueiredo Dias, 1993, p. $665^{20}$ ). Deve conter os factos integrantes do crime, o dia, a hora, o local e circunstâncias em que ocorreu e ainda, se possível, a identidade completa do(s) arguido(s), ofendido(s) e testemunha(s) e os meios de prova disponíveis ${ }^{21}$, devendo ainda conter a indicação de que o queixoso se quer constituir assistente, o que, não sendo obrigatório, conferirá ao titular do direito de queixa vários poderes de intervenção processual, sendo o mais importante o de interpor recurso das decisões que o afectem, mesmo que o Ministério Público o não tenha feito. O direito de queixa extingue-se pelo mero decurso do prazo de seis meses, sem necessidade de qualquer manifestação de vontade nesse sentido, a contar da data em que o titular teve conhecimento do facto e dos seus autores, ou a partir da morte do ofendido, ou da data em que ele se tornou incapaz (se nestes casos, não se tiver já extinguido o direito de queixa). Sendo vários os titulares do direito de queixa, o prazo conta-se autonomamente para cada um deles. Em caso de crime continuado, a solução mais correcta parece ser a de se considerar o prazo para a queixa «relativamente a cada um dos actos parciais em que aquele crime se desdobra, não podendo o procedimento ter lugar relativamente aos actos parciais de que não tenha havido queixa tempestiva». (Figueiredo Dias, 1993, ob. cit., p. 675). Quando a queixa for feita a entidade diferente do Ministério Público (v.g. à polícia), deverá ser remetida àquela entidade no mais curto prazo, já que a ele compete o exclusivo da promoção processual, sem prejuízo da prática, pela polícia, dos actos cautelares e urgentes para assegurar os meios de prova.

A queixa pode ser objecto de renúncia expressa (consiste na declaração inequívoca de que não se quer exercer o direito de queixa) ou tácita (consiste na prática de factos de onde a renúncia naturalmente se deduza).

Além disso, pode ter lugar a desistência da queixa, através da qual aquele que exerceu o direito de queixa pode desistir dele. Mas tem de o fazer até à publicitação da sentença em primeira instância sem que haja oposição expressa por parte do arguido (a desistência é um acto bilateral, implicando que o arguido seja notificado para se pronunciar sobre a desistência). A desistência é irretractável, impedindo a renovação da queixa.

Nos crimes em que se exige que o ofendido deduza acusação particular ${ }^{22}$, segue-se, com as devidas adaptações, o regime aplicável à queixa.

20 Figueiredo Dias, J. (1993): As consequências jurídicas do crime. Lisboa: Editorial Notícias/ Aequitas.

21 A denúncia contém, na medida possível, a indicação dos elementos referidos nas alíneas do n. ${ }^{\circ} 1$ do art. $243^{\circ}$ do CPP (n. ${ }^{\circ} 3$ do art. $246^{\circ}$ do CPP).

22 Crimes de difamação (art. $180^{\circ}$ do $\mathrm{CP}$ ), injúrias (art. $181^{\circ}$ do $\mathrm{CP}$ ), e de ofensa à memória de pessoa falecida (art. $185^{\circ}$ do CP). 


\section{Especificidades da intervenção médico-legal a propósito da prática de crimes contra a integridade psicofísica}

\section{Crimes públicos e crimes semi-públicos}

Interessa-nos aqui focalizar algumas especificidades da intervenção dos serviços médico-legais no domínio da realização de exames a pessoas vítimas de crimes, públicos e semi-públicos, com determinadas características e em situações de urgência:

a) cujo resultado típico se traduza num (ou implique) dano à saúde das pessoas, tomada esta, na definição dada pelo preâmbulo dos estatutos da Organização Mundial de Saúde, como «ausência de completo bemestar físico, mental e social»;

b) que reclamem a célere avaliação médico-legal das lesões resultantes da agressão, para efeitos probatórios.

Desses crimes, destacam-se, pela frequência estatística da correspondente intervenção médico-legal, os seguintes tipos legais:23

\section{Crimes públicos ${ }^{24}$ :}

- Violência doméstica (art. $152^{\circ}$ do CP), Maus-tratos (art. $152^{\circ}$ - A do CP); - Abuso sexual de pessoa internada (art. $166^{\circ}$ do CP);

23 A Procuradoria-Geral da República, através de Despacho de 15 de Janeiro de 2008 de Sua Excelência o Conselheiro Procurador-Geral da República, emitiu directivas e instruções genéricas em matéria de execução da lei sobre política criminal tendo em vista a prossecução dos objectivos, prioridades e orientações de política criminal definidos pela Lei n. ${ }^{\circ}$ 51/2007, de 31 de Agosto, para o biénio 2007/2009. Nos termos do n.'s I.1 e I.2 do documento emanado da PGR será concedida especial prioridade à investigação, entre outros, dos processos relativos à criminalidade violenta contra as pessoas, designadamente ofensas à integridade física graves, crimes contra a liberdade e autodeterminação sexual, e também dos relativos a crimes contra bens jurídicos individuais de pessoas idosas, crianças e deficientes, tendo em conta a sua especial vulnerabilidade. Constata-se, pois, que os crimes que agora se elencam encontram acolhimento no rol de prioridades da investigação criminal (excepção feita às situações de violência doméstica dirigida a cônjuge ou equiparado, não abrangidas pelo referido documento da PGR).

24 Através da Lei n. ${ }^{\circ}$ 59/2007, de 4 de Setembro (que entrou em vigor em 15-9-2007), foram aprovadas alterações ao Código Penal aprovado pelo Decreto-Lei n. ${ }^{\circ} 400 / 82$, de 23 de Setembro, traduzidas, designadamente, na alteração de tipos legais de crimes, na introdução de novos tipos legais de crimes, e na modificação dos respectivos requisitos do procedimento criminal, passando alguns desses crimes a incluir-se na qualificação doutrinária de crimes públicos. O universo de ilícitos criminais que sofreram inovação inclui a problemática da violência doméstica, dos maus-tratos e dos abusos sexuais de menores, situações que diariamente justificam a intervenção processual dos serviços médico-legais no âmbito das suas atribuições legais, processuais e estatutárias. 
- Coacção sexual (art. $163^{\circ}$ do CP), Violação (art. $164^{\circ}$ do CP), Abuso sexual de pessoa incapaz de resistência (art. $165^{\circ}$ do $\mathrm{CP}$ ), se cometidos contra menor de 18 anos (art. $178^{\circ}$, n. $^{\circ} 1$, do $\mathrm{CP}$ );

- Abuso Sexual de Crianças (art. $171^{\circ}$ do CP), Abuso Sexual de Menores Dependentes (art. $172^{\circ}$ do $\mathrm{CP}$ ).

Crimes semi-públicos:

- Ofensas à integridade física simples (art.143 do CP);

- Crimes de natureza sexual contra maiores (art.s $163^{\circ}$ a $165^{\circ}$ do $\mathrm{CP}$ ).

Detenhamo-nos brevemente sobre cada um dos referidos crimes (públicos e semi-públicos), no que respeita aos bens jurídicos que visam proteger.

Crime de Violência Doméstica (art. $152^{\circ}$ do Código Penal): o bem jurídico protegido pela incriminação é a saúde, nas suas vertentes física, psíquica e mental, fundada na dignidade da pessoa humana, incriminando-se condutas que derivam de contextos diversos que têm em comum, de forma imediata ou mediata, uma relação familiar ou equiparada.

Crime de Maus-Tratos (art. $152^{\circ}$ - A do CP): o bem jurídico protegido pela incriminação é a saúde, nas suas vertentes física, psíquica e mental, fundada na dignidade da pessoa humana, incriminando-se condutas praticadas em meio institucional ou no âmbito de uma relação de cuidado.

Crimes de Coacção sexual (art. $163^{\circ}$ do CP), Violação (art. $164^{\circ}$ do $\mathrm{CP}$ ), Abuso sexual de pessoa incapaz de resistência (art. $165^{\circ}$ do $\mathrm{CP}$ ), se cometidos contra menor de 18 anos (art. $178^{\circ}$, n. ${ }^{\circ} 1$, do $\mathrm{CP}$ ): o bem jurídico protegido é a liberdade sexual.

Crime de Abuso Sexual de Pessoa Internada (art. $166^{\circ}$ do CP): o conteúdo essencial do bem jurídico caracteriza-o como o da independência sexual da pessoa internada ${ }^{25}$, incriminando-se a prática de actos sexuais de relevo por pessoa que exerça funções no estabelecimento de saúde, assistência ou tratamento em que a pessoa se encontre

Crime de Abuso Sexual de Crianças (art. $171^{\circ}$ do $\mathrm{CP}$ ): o bem jurídico protegido é a autodeterminação sexual dos menores de 14 anos, incriminandose a prática, com estes menores, de actos sexuais e de condutas censuráveis, de índole sexual.

Crime de Abuso Sexual de Menores Dependentes (art. $172^{\circ}$ do $\mathrm{CP}$ ): neste tipo legal o bem jurídico protegido é a autodeterminação sexual dos menores entre 14 e 18 anos, incriminando-se a prática, com estes menores,

25 Figueiredo Dias, J. (1999): Comentário Conimbricense do Código Penal - Parte Especial. Coimbra: Coimbra Editora 
de actos sexuais e de condutas censuráveis, de índole sexual, quando tais condutas sejam levadas a cabo por aqueles a quem os menores hajam sido confiados para educação ou assistência.

Crimes de Coacção sexual (art. $163^{\circ}$ do CP), Violação (art. $164^{\circ}$ do $\mathrm{CP}$ ), Abuso sexual de pessoa incapaz de resistência (art. $165^{\circ}$ do $\mathrm{CP}$ ), se cometidos contra maior de 18 anos: visa proteger-se a liberdade sexual através da incriminação de diversas condutas de natureza sexual.

Crime de Ofensa à integridade física simples (art. 143 do CP): protege-se a saúde da pessoa: a integridade física e psíquica.

\section{Denúncia e recebimento de denúncia}

No âmbito da intervenção pericial dos serviços médico-legais para realização de exames e perícias na sequência da prática de factos susceptíveis de se traduzirem nos tipos legais de crimes acima enunciados, emergem da especial relação funcional existente entre o INML, I.P., e as autoridades judiciárias - para além do dever de realização de exame médico-legal para acautelar o registo médico-legal de lesões físicas decorrentes do acto sofrido pela vítima (incluindo a resposta às solicitações feitas em sede de realização de perícias médico-legais urgentes) - alguns deveres para o Instituto, de entre os quais se destacam:

a) o dever de denunciar situações susceptíveis de serem consideradas como crimes públicos;

b) o dever de receber:

a) denúncias de crimes de natureza pública;

b) queixas de crimes de natureza semi-pública.

Podem prefigurar-se então, a propósito da denúncia do crime, as seguintes situações no âmbito da intervenção pericial do INML, I.P:

a) crimes públicos:

a) independentemente do recebimento de denúncia, o INML, I.P. ${ }^{26}$, detecta uma situação susceptível de enquadramento como crime público: o INML, I.P., encontra-se obrigado a denunciar o crime ao Ministério Público;

b) a vítima, ou outras pessoas, denunciam o crime ao INML, I.P., nos termos do n. ${ }^{\circ} 1$ do art. $4^{\circ}$ da Lei n. ${ }^{\circ} 45 / 2004$, de 19 de Agosto: o INML, I.P., encontra-se obrigado a transmitir essa denúncia, no mais curto prazo, ao Ministério Público;

b) crimes semi-públicos: tratando-se de uma queixa (relativa a prática de um crime de natureza semi-pública e desde que efectuada por pessoa

26 Leia-se: o perito, ou outro profissional, que actue em nome deste Instituto. 
com legitimidade para tal), o INML, I.P., encontra-se, por igual, obrigado a transmitir essa queixa ao Ministério Público.

\section{Realização de exame sem prévia existência de processo penal}

Poderá haver lugar à realização de exame pericial sem prévia existência de processo judicial (processo de inquérito penal) ou denúncia de crime a órgão de polícia criminal, em sede de prática de actos cautelares necessários e urgentes para assegurar os meios de prova (cf. o n. ${ }^{\circ} 2$ do art. $4^{\circ}$ e o n. ${ }^{\circ} 1$ do art. $13^{\circ}$, ambos da Lei n. ${ }^{\circ}$ 45/2004, de 19 de Agosto).

Com efeito, a realização de perícias médico-legais urgentes ${ }^{27}$ pode ser directamente solicitada aos serviços médico-legais pelas vítimas de crimes, ao abrigo do art. $4^{\circ}$, n. ${ }^{\circ} 1$, da Lei n. ${ }^{\circ} 45 / 2004$, de 19 de Agosto, mesmo sem prévia existência de um processo de inquérito penal.

Tal ocorrerá através, nomeadamente, da realização de exame de clínica forense na pessoa da vítima, com eventual colheita e preservação de vestígios, o que pode ocorrer nas instalações das Delegações do INML, I.P., ou dos gabinetes médico-legais delas dependentes, ou ainda nos serviços hospitalares, podendo ser solicitada, a qualquer hora, pelos órgãos de polícia criminal e pelas autoridades judiciárias (ou ainda, eventualmente, pelos serviços hospitalares). ${ }^{28}$

A intervenção pericial médico-legal nas situações em que não existe processo penal merece uma abordagem diferenciada consoante se esteja em presença de crimes públicos ou de crimes semi-públicos.

\section{Crimes públicos}

Sempre que os peritos (médico-legais e forenses) do INML, I.P., (das delegações ou gabinetes médico-legais) tenham fundada suspeita ou detectem indícios

27 Consideram-se perícias médico-legais urgentes aquelas em que se imponha assegurar com brevidade a observação de vítimas de violência, tendo designadamente em vista a colheita de vestígios ou amostras susceptíveis de se perderem ou alterarem rapidamente (definição dada pelo art. 13, n. ${ }^{\circ} 1$, da Lei n. ${ }^{\circ}$ 45/2004, de 19 de Agosto). As perícias médico-legais urgentes são realizadas nos serviços médico-legais, ou em estabelecimentos oficiais de saúde, consoante a intervenção pericial solicitada deva ter lugar dentro ou fora do horário normal de funcionamento daqueles serviços.

28 Veja-se a propósito o disposto no art. $13 .^{\circ}$ da Lei n. ${ }^{\circ}$ 45/2004, de 19 de Agosto, sobre o local de realização dos exames periciais urgentes, aqui se destacando a disposição do n. ${ }^{\circ} 5$ desse artigo: «5 - As perícias médico-legais urgentes relativas a vítimas de agressão realizadas fora das horas normais de funcionamento dos serviços médico-legais poderão ter lugar em serviços de urgência de hospitais públicos ou outros estabelecimentos oficiais de saúde, dependendo, neste último caso, da prévia celebração de protocolos de cooperação entre estes e o Instituto.». 
(físicos ou de índole psíquica) da prática do crime de violência doméstica (art. $152^{\circ}$ do $\left.\mathrm{CP}\right)$, maus tratos $\left(152^{\circ}-\mathrm{A}\right.$ do $\left.\mathrm{CP}\right)$, de crimes de natureza sexual em vítimas menores de 18 anos (art.s $163^{\circ}$ a $165^{\circ}$ do CP), e de abuso sexual de menores (art. $171^{\circ}$ a $172^{\circ}$ do $\mathrm{CP}$ ), justifica-se, pela natureza pública de tais crimes, a adopção (pelo INML, I.P.) de um conjunto de procedimentos através dos quais os peritos possam detectar precocemente tais casos e proceder ao seu correcto encaminhamento para as entidades competentes.

Assim:

1 - Quando o perito médico, no exercício das suas funções periciais no âmbito da clínica forense, for chamado a examinar vítima da prática de ilícitos criminais de natureza pública, tais como

- Crime de Violência doméstica - art. $152^{\circ}$;

- Crime de Maus-tratos - art. $152^{\circ}$-A;

- Crimes sexuais dos art.s $163^{\circ}$ a $165^{\circ}$, em que a vítima seja menor de 18 anos;

- Crime de abuso sexual de pessoa internada - art. $166^{\circ}$;

- Crime de abuso sexual de crianças - art. 171 ${ }^{\circ}$;

- Crime de abuso sexual de menores dependentes - art. $172^{\circ}$., deve receber denúncia do crime (caso ainda não tenha sido efectuada) e transmiti-la de imediato ao Ministério Público. ${ }^{29}$

2 - Perante qualquer das situações de vitimação referidas no número anterior que até ao momento da intervenção pericial não tenham ainda sido denunciadas, ou sequer sinalizadas, deve o perito médico-legal, se obtiver fundada suspeita da sua prática (através da observação do examinando, ou através de quaisquer outros elementos, designadamente documentos ou testemunhas) denunciar o crime (ou a suspeita de crime) ao Ministério Público.

3 - A denúncia deve ser efectuada através de documento próprio ("Auto de denúncia” $)^{30}$, e remetido ao Ministério Público via Fax $^{31}$.

4 - A denúncia tem lugar independentemente da vontade da vítima ou da realização do exame pericial.

29 Importa salientar que no caso do art. $173^{\circ}$ do CP (actos sexuais com menores entre 14 e 16 anos), mesmo face à natureza semi-pública deste ilícito criminal, o INML, I.P., avaliando a gravidade dos factos e dos efeitos da sua prática sobre a vítima, poderá comunicar a situação ao Ministério Público, tendo em vista permitir a esta autoridade judiciária a ponderação da decisão de, na defesa do interesse do ofendido, dar início ao procedimento criminal, nos termos do n. ${ }^{\circ} 5$ do art. $113^{\circ}$ do $\mathrm{CP}$.

30 O examinando (ou o seu representante legal, no caso de examinando ser menor ou não possuir discernimento paras entender o significado e o alcance do exercício do direito de queixa) deverá declarar, no Auto de Denúncia, que pretende seja instaurado procedimento criminal.

31 Se não estiver em uso a transmissão por correio electrónico. 
5 - Se a vítima for menor ou incapaz e o representante legal obstar à realização do exame, deve esse facto ser prontamente comunicado ao Ministério Público (no documento de denúncia do crime, ou em documento autónomo, se a denúncia já tiver sido feita).

6 - Em caso de vítimas menores, deve comunicar-se a situação à Comissão de Protecção de Crianças e Jovens da área de residência do menor, utilizando o modelo próprio para a respectiva sinalização.

7 - A denúncia e a comunicação referidas devem ser acompanhadas, sempre que possível, do relatório pericial do exame efectuado, ainda que preliminar.

8 - Em caso de recolha de amostras de vestígios, deve(m) ser realizada(s) a(s) correspondente(s) perícia(s), que serão juntas ao relatório pericial de clínica forense (ou posteriormente enviadas em aditamento a relatório preliminar de clínica forense).

9 - Sem prejuízo do disposto nas normas e metodologias periciais em vigor sobre a realização dos exames de clínica forense de natureza sexual, os pedidos de intervenção que nesta matéria sejam feitos aos peritos médico-legais em sede de actos urgentes deverão, na medida do possível, ser sempre satisfeitos, dado que apenas o efectivo exame permite objectivamente afirmar a inexistência de vestígios (não obstante o teor da informação existente sobre o período de tempo decorrido após a alegada data da última agressão).

\section{Crimes semi-públicos}

Os serviços médico-legais têm competência para receber queixas de crimes de natureza semi-pública, ao abrigo do disposto no art. $4^{\circ}$ da Lei n. ${ }^{\circ}$ 45/2004, de 19 de Agosto.

Atenta a especificidade das situações de vitimação sexual e a especial natureza de que se reveste a respectiva resposta pericial médico-legal, entende-se que se deve alargar o âmbito de intervenção dos serviços médico-legais para além do que corresponde à expressão literal da disposição do mencionado art. $4^{\circ}$ da Lei n. ${ }^{\circ} 45 / 2004$, de 19 de Agosto.

Assim, quando o perito médico em escala de actos urgentes for contactado por serviço de saúde ou órgão de polícia criminal para realizar (nas instalações dos serviços médico-legais ou fora delas) exame médico-legal em vítima de crime cujo procedimento criminal dependa de queixa (no caso, exames de natureza sexual em maiores de 18 anos) $)^{32}$, deve satisfazer o respectivo pedido,

32 Referimo-nos aos crimes dos art.s $163^{\circ}$ a $165^{\circ}$ do CP. 
independentemente da prévia existência de queixa ${ }^{33}$, sempre que a intervenção pericial for urgente, isto é, necessária para preservar, ou documentar, os vestígios e outros sinais da prática do crime que, na ausência dessa intervenção precoce se perderiam, impossibilitando a respectiva avaliação médico-legal. Em tais casos, deve ser efectuado o exame para preservação das evidências físicas e (ou) biológicas, comunicando-se aos competentes serviços do Ministério Público a realização do exame, a existência de eventuais amostras biológicas, e que o relatório pericial (ainda que preliminar) estará disponível se solicitado, não se procedendo contudo à realização de exames laboratoriais se estes não forem requeridos pela autoridade judiciária competente.

\section{Realização de exame na pendência de processo judicial}

Existindo processo judicial (processo de inquérito penal) - ou denúncia de crime a órgão de polícia criminal - prévio à intervenção dos serviços médico-legais (em sede de realização de exame médico-legal solicitado por órgão de polícia criminal ou pelo Ministério Público), deverá ser observado o seguinte:

a) Sempre que durante ou por causa da realização de exame médico-legal de clínica forense solicitado por órgão de polícia criminal ou autoridade judiciária, o perito médico recolha suspeitas (confirmadas através do exame físico ou por outro meio):

a) de que o examinando é vítima de crime de natureza pública não identificado no processo no qual se suscitou a intervenção pericial, tal deve constar do relatório pericial correspondente ao exame solicitado, o qual deve ser de imediato remetido via fax aos serviços do Ministério Público competentes, com identificação do NUIPC (Número Único de Identificação de Processo Crime).

b) de que pessoa do agregado familiar do examinando é vítima de crime de natureza pública não denunciado, deve transmitir de imediato essas suspeitas ao Ministério Público, sob a forma de denúncia, acompanhada, sendo caso disso, de relatório pericial (ainda que preliminar), fazendo referência ao processo no âmbito do qual tais suspeitas se verificaram.

b) No caso do examinando ser menor, tais suspeitas deverão ainda ser comunicadas à CPCJ da área de residência do menor;

c) A denúncia e a comunicação referidas, respectivamente, nas anteriores alíneas a)a), a)b), e b), devem ser efectuadas através do preenchimento

33 Ou seja, mesmo que a vítima, ou o seu representante legal, não exerça formalmente o direito de queixa. 
e assinatura do respectivo documento próprio (para "denúncia", ou "comunicação");

d) Todas as faltas à realização de exames previamente marcados devem ser imediatamente comunicadas, via fax, ao Ministério Público (ao magistrado competente, se o processo já tiver sido registado e autuado como inquérito pelo Ministério Público).

\section{Procedimentos comuns (a crimes públicos e semi-públicos)}

1 - Os casos urgentes impõem a imediata articulação entre os serviços médico-legais, os órgãos de polícia criminal e, eventualmente, entidades de apoio à vítima, no sentido de assegurar as condições e os pressupostos para que o Ministério Público, reunindo os necessários elementos de prova, possa promover medidas que visam a protecção da vítima e a perseguição criminal do suspeito autor do crime, designadamente, a emissão de mandados de detenção, propondo igualmente ao Juiz as medidas de coacção que entenda serem de aplicar ao arguido.

2 - A realização dos exames médico-legais pressupõe o consentimento do examinando, o qual deve ser prestado, sempre que possível, por escrito, através de modelo de documento próprio para o efeito.

2 - As denúncias de crimes recebidas pelo INML, I.P., devem ser remetidas aos Serviços do Ministério Público da comarca onde os factos (ou o último facto) ocorreram.

3 - Sempre que haja lugar à realização de análise laboratorial de pesquisa de produtos biológicos, o Serviço Técnico do INML, I.P., que a realizou (ou que eventualmente a tenha solicitado a uma terceira entidade) deverá entregar o respectivo relatório ao Serviço de Clínica Forense, que o remeterá ao Ministério Público, acompanhando relatório pericial de clínica forense, preliminar ou concluído.

\section{Nota final}

Os procedimentos que deixamos sugeridos e que sejam observados no âmbito da intervenção pericial dos serviços médico-legais devem respeitar a articulação que em cada caso concreto haja de ser feita, para celeridade do processo e defesa do interesse das vítimas, com os órgãos de polícia criminal, com o Ministério Público e com os tribunais.

Resumo: Crimes públicos e crimes semi-públicos: quando denunciar?

Tomando como referência um conjunto de situações de prática de crimes que se caracterizam por provocar dano à saúde das pessoas, nas quais se reclama a célere avaliação médico-legal 
das lesões resultantes da agressão e colheita de vestígios biológicos para efeitos probatórios, e considerando a distinção entre crimes de natureza pública e crimes de natureza semi-pública e o respectivo tratamento processual, apresenta-se um conjunto de conceitos e de procedimentos de actuação de forma a permitir ao perito médico-legal perceber o enquadramento jurídico-processual das situações de vitimação para as quais é chamado a intervir, e a facilitar a detecção precoce e o correcto encaminhamento daquelas situações, no respeito pelos direitos, liberdades e garantias dos cidadãos.

Palavras-chave: Serviços-médico-legais; dever de denúncia; vitimas de crime.

Summary: Public crimes and semi-public crimes: when to denounce?

Starting from a set of crimes (offences) characterised by causing harm to the health of people implying an early medical expert evaluation and the collection of samples for evidence and proof purposes, and considering the different procedural conditions of those various crimes, the author presents a set of concepts and procedures in order to enable the medico-legal expert to fully understand the legal and procedural context of the situations in which he is called to intervene, and to correctly detect and treat them, in the respect of the constitutional rights of individuals.

Key-words: Forensic examination; obligation to denounce; crime victms.

Résumé: Crimes publiques et crimes semi-publiques: quand dénoncer?

En prenant comme référence un ensemble de situations de pratique de crimes qui se caractérisent par provoquer dommage à la santé des personnes, chez lesquelles on réclame la rapide évaluation médico-légale des lésions résultantes de l’agression pour des effets probatoires, et tenant compte des distinctes conditions de procédure pénale selon le type de crime, on présente un ensemble de concepts et de procédures dactuation de façon à permettre à l’expert médico-légal de percevoir l’encadrement juridico-processuel des situations de victimisation pour lesquelles il est appelé à intervenir, et à faciliter la détection précoce et le correct cheminement de ces situations, dans le respect pour les droits, libertés et garanties des citoyens.

Mots-clés: Expertise médico-légale; victimes de crime; devoir de dénoncer.

\author{
Pedido de separatas: \\ DIOGO PINTO DA COSTA \\ diogo.costa @inml.mj.pt
}

